Daimon. Revista Internacional de Filosofía, Suplemento 5 (2016), 313-321

ISSN: 1130-0507 (papel) y 1989-4651 (electrónico)

http://dx.doi.org/10.6018/daimon/272471

\title{
¿Es posible una narración sin cuerpo?
}

\author{
It is possible a story without bodies?
}

\author{
SANDRA PÉREZ CASTANEEDA*
}

\begin{abstract}
Resumen: ¿Es posible una narración sin cuerpo? Todo personaje porta un cuerpo, mueve un cuerpo, desarrolla un cuerpo a través de un espacio y un tiempo que evolucionan con la trama. Paul Ricoeur dice que solo una historia narrada dice el quién de la acción, la pregunta por el ser se contesta narrando una historia. La identidad se hace comprensible, inteligible a través de la narración. Así que el narrar tiene implicaciones ontológicas. Todo personaje narrativo es un Dasein arrojado a un mundo.
\end{abstract}

Palabras clave: Cuerpo, personaje, espacio, tiempo, identidad, ontología, Dasein, mundo.

\begin{abstract}
It is possible a story without bodies? Every character carries a body, moves a body, develops a body through space and time that evolve with the plot. Paul Ricoeur says that only a story told the who of the action. The question of being is answered by narrating. The identity becomes comprehensible, intelligible through the narration. So it has ontological implications. All narrative character is a Dasein thrown into the world.

Clues: Body, character, space, time, identity, ontology, Dasein, world.
\end{abstract}

La conjunción cuerpo-arte sugiere de primeras lo plástico: pintura, escultura, fotografía. También lo escénico, en el teatro. O la combinación de ambos en el cine. Estas artes representan a través de formas que nos conduce a un referente con el que guardan distintos grados de correlato o correspondencia. En todas ellas la presencia del cuerpo es patente mientras que en otras, como la música, no. En las artes de la palabra el cuerpo se camufla. Ocurre que al articularse a través de las palabras, por la abstracción y la arbitrariedad entre significante y significado, estas artes confunden y llevan al olvido de que se compone de signos que representan cuerpo, imitan cuerpo. La lírica arrastra un grado de abstracción mayor que la narración. Entre lo plástico-escénico y lo lírico se sitúa lo narrativo en una posición intermedia fácilmente quebrantable por la libertad formal generada y exigida al arte para sobrevivir y reinventarse a sí mismo. Algunas artes pretenden perder su dependencia de la palabra que la sustenta. El cine y el teatro, salvo algunas experiencias experimentales, se basan en un texto que maneja y caracteriza cuerpos, a veces invisibles en él, hasta alcanzar la posterior representación que le da forma. Una forma que guarda similitudes con lo real y con lo representado. Inapreciable muchas veces en ese texto, germen de lo escénico, que encierra corporeidad.

Fecha de recepción: 10/06/2016. Fecha de aceptación: 27/07/2016.

* Universidad de Sevilla. Estudiante.sanpercas@gmail.com. Líneas de investigación: relaciones entre filosofía y narrativa. 
La definición que Aristóteles da a la trama narrativa en su Poética es la de mímesis, imitación de la naturaleza y de la vida. Todas las artes son imitativas, imitan a la vida, significándola las narrativas por medio de la palabra y la acción. «De todos los elementos, el más importante es la organización de los hechos porque la tragedia no es imitación de los seres humanos sino de sus acciones y de la vida, la felicidad y la infelicidad están en la acción» ${ }^{1}$. «Un parecerse a» que puede, ahondando en la esencia, bandearse entre «lo que es» y «lo que no es» o «es como», en una tensión de sentidos que produce una significación emergente. Dice Aristóteles en Poética: «La actividad mimética es connatural a los seres humanos desde la infancia (...). En segundo lugar, todos los seres humanos disfrutan con las imitaciones $»^{2}$. «El imitar es conforme a nuestra naturaleza $»^{3}$. Una imitación a la vida, al ser humano y a su mundo, convertidos en objetos y sujetos intercambiables, de manera tan radical como la lograda por las artes escénicas y plásticas. Naturaleza, universo, mundo, son antónimos de alma, espíritu, conciencia, dice Paul Ricoeur ${ }^{4}$, que añade que en narrativa son necesarios ambos accesos 5 : el exterior y el interior. ¿En qué polaridad está el cuerpo? Podríamos con-testar que en la primera, o que en ambas. Como en cajas chinas, unas guardan a las otras, y todas son materias que evaden el control del conocimiento humano. Mundo/sujeto, objeto/sujeto. Será Heidegger el que aúna estos opuestos en el Dasein en el que naturaleza y mundo son constitutivos del ser,Fpantharinateírnante lengrajęplosisiǵnos y el texto serían el polo objetivo de una conciencia que obedece a una intención creadora. La narración es la descripción de una serie de vicisitudes que afectan a un sujeto, o a varios, con diferentes cambios, acciones o fenómenos en un entorno, un mundo durante un lapso de tiempo. Desde un punto de visto fenomenológico no hay narración sin cuerpo. Nos conocemos como objetos, dice Kant. La narración sostiene el cuerpo de los sujetos/objetos personajes y también el cuerpo del autor y también del contador o contadores de la historia. El sujeto que cuenta y se interroga por la cosa debe ser considerado también parte de la cosa: un narrador incorpóreo, con voz en tercera persona, generalmente omnisciente o desde la perspectiva de un observador exterior con cierto grado de deficiencia en su narrar sobre los otros y el mundo; o un narrador en primera o segunda persona que expande un yo fenomenológico de vivencias propias o ajenas; sueños, deseos, frustraciones, memoria, recuerdos; o el narrador reflexivo que en sus especulaciones, reflexiones, pensamientos, ideas, puede discurrir asemejándose a las meditaciones dubitativas de los grandes pensadores. El yo en sí sujeto y objeto de sí mismo. El yo absoluto kantiano, que actúa y padece; el yo pienso de la percepción trascendental y el yo fenoménico afectado por cualquier objeto; todos ellos se dan en narración. Esas voces se vehiculan a través de palabras, tonos, matices, expresiones, gramática dan cuenta del sujeto y, a su vez, de su cuerpo. El habla es un acto como afirma Austin. En las palabras existe el cuerpo.

«No hay carácter en los discursos en los que el que habla ni prefiere ni rechaza alguna cosa: mientras que sí hay pensamiento allí donde se prueba que algo es o no es o donde se

\footnotetext{
ARISTÓTELES (2004) Poética. Trad y Ed. Salvador Mas. Biblioteca nueva. Madrid, p. 79 [15].

ARISTÓTELES (2004) Poética. Trad y Ed. Salvador Mas. Biblioteca nueva. Madrid, p. 70 [5].

ARISTÓTELES (2004) Poética. Trad y Ed. Salvador Mas. Biblioteca nueva. Madrid, p. 71 [20].

RICOEUR, PAUL (1996) Tiempo y narración III. El tiempo narrado. Siglo veintiuno. Madrid, p. 646.

5 RICOEUR, PAUL (1987) Tiempo y narración II. Configuración del tiempo en el relato de ficción. Cristiandad. Madrid, p. 643.
} 
manifiesta algo universal» ${ }^{6}$. En los diálogos de los personajes y en sus pensamientos hay cuerpo. Son parte de su caracterización. El habla es inseparable de lo corporal, al igual que las circunstancias sociales y económicas de los sujetos y de los personajes. Para Ortega y Gasset en el cuerpo quedan inscritas las marcas del entorno social. El obrero trabaja con sus manos, con el cuerpo. El capataz y el médico con la mente. La fortaleza del soldado le prepara para el combate. Lo específico de cada cuerpo define hábitos, psicología, el modo de ser, y también al revés. La inconstancia y la pereza del obeso. La fragilidad manifiesta de la víctima. En la corpulencia del malvado reside su cobardía. En la mirada, su intencionalidad. El movimiento de las acciones dibuja el cuerpo del personaje. Su tirantez, su relajación, su agitación, su comodidad, su expectación, su cansancio, su fuerza, su ligereza, su felicidad. El cabello, el rostro, el rictus, el semblante. Su estado y percepciones; el frío y el calor. El propio desarrollo de la trama muta sus cuerpos. «Por carácter y pensamiento decimos que las acciones son unas y otras; carácter y pensamiento son, en efecto, las dos causas naturales de la acción» ${ }^{7}$.

El libro es un objeto físico, una materia, un cuerpo sea papel o formato ebook que tiene una forma, un tiempo y un lugar. Para su uso predispone un cuerpo, el del lector, a un movimiento físico, el requerido para la lectura. Leer requiere de los ojos, de las manos, de los dedos, de la mente, de toda una neurotransmisión de células, que dan lugar a toda una gama de acciones mentales: concentración, comparación, relación, memoria, proyección, reconocimiento, percepción, discriminación, entre otras. Reconocer es parte del esqueleto inteligible del placer de la representación para Aristóteles ${ }^{8}$. El leer a su vez produce respuestas corporales: placer, dolor. Para Heidegger el comprender tiene dimensión ontológica. La lectura nunca es un acontecimiento externo ni contingente ${ }^{9}$, dice Paul Ricoeur. «Prescindiendo de la lectura, el mundo del texto sigue siendo una trascendencia en la inmanencia. Su estatuto ontológico queda en suspenso a la espera de la lectura en donde el dinamismo de configuración acaba su recorrido. Y más allá de la lectura, en la acción efectiva, donde la configuración cambia a refiguración», prosigue Ricoeur. El lector tiene la posibilidad de recuperar la forma de los cuerpos contenidos en los textos e imitar sus acciones. Para Aristóteles las tramas son como criaturas vivientes, tienen vida propia porque tienen su propia naturaleza y cumplen con una finalidad. «En lo que hace la imitación narrativa y métrica es preciso organizar las tramas de manera dramática, como en las tragedias, y que versen sobre una sola acción, entera y completa, que tenga principio, medio y fin, de modo que, como si fuera una criatura viviente entera, produzca el placer que le es propio» ${ }^{10}$.

Arrancamos afirmando que cada personaje porta y mueve un cuerpo. Una narración es el desarrollo espacio temporal de un cuerpo. Si nos centramos en el género narrativo por excelencia de nuestro tiempo, la novela, ya sea en su vertiente aventuras o la realista, tomando la clasificación ortegeriana, son los cuerpos de los personajes los que sobrellevan y sufren las vicisitudes de la acción de forma más o menos manifiesta. No es casualidad que en La metamorfosis (1915), Kafka, represente la progresiva enajenación del protagonista

6 ARISTÓTELES (2004) Poética. Trad y Ed. Salvador Mas. Biblioteca nueva. Madrid, p. 81 [10].

7 ARISTÓTELES (2004) Poética. Trad y Ed. Salvador Mas. Biblioteca nueva. Madrid, p. 78 [5].

8 ARISTÓTELES (2004) Poética. Trad y Ed. Salvador Mas. Biblioteca nueva. Madrid, p. 98.

9 RICOEUR, PAUL (1996)Tiempo y narración III. El tiempo narrado. Siglo veintiuno. Madrid, p. 866.

10 ARISTÓTELES (2004) Poética. Trad y Ed. Salvador Mas. Biblioteca nueva. Madrid, p. 120 [10]. 
por medio de una trasmutación desafortunada que lo transfigura en bicho, en una especie de cucaracha. Transfiguración que arranca en el cuerpo y culmina en el espíritu. El cuerpo como huella o como signo. La mente hace cuerpo y el cuerpo mente; materia de trabajo filosófico y literario. Tampoco es azaroso que la muerte como acabamiento corpóreo sea el destino común de muchos personajes; o que una muerte corpórea no constituya una muerte total si no que la presencia incorpórea se mantenga como en Los muertos (Dublineses, 1914, James Joyce); o que el desenlace narrativo no alcance la extinción del cuerpo, pero sí su decrepitud. Lo literario-narrativo arroja mucha significación acerca de la dualidad cuerpo y alma, y su tesis contraria, el monismo. Las aporías sobre cuerpo/mente, cuerpo/alma, materia/espíritu.

Durante mi ponencia en el VII Congreso de la SAF sobre Filosofía y Cuerpo trabajamos la presencia del cuerpo en tres textos narrativos de los que soy autora. El arranque de la novela La ciudad que rompe sueños ${ }^{11}$ describe la disposición de los cuerpos de las personas que viajan en un vagón de metro a través de dos detalles: las posiciones de sus manos y el uso de mascarillas que ocultan sus rostros. Mediante esas pinceladas descriptivas se simboliza la vida en esa ciudad, contaminada, altamente poblada y donde la muerte más común es el suicidio, por lo que se organiza bajo unas férreas medidas de seguridad para evitarlos. El enmascaramiento de las caras y la desgana de las manos colgantes trasladan al texto la atmósfera asfixiante de la vida en esa ciudad. Cubrirse la cara tiene consecuencias directas en la comunicación interpersonal y en el conocimiento. Hay un área del cerebro especializada en el reconocimiento de las caras. Describiendo los cuerpos se refleja el desánimo de vida de los habitantes.

El segundo ejemplo fue un relato, La burla ${ }^{12}$, del recopilatorio A los fantasmas se les mata publicando, en el que se trata el tema de la locura. El miedo y la locura son estados revelan una correspondencia entre cuerpo y alma. Al igual que la ira o la culpa. En este relato se narra cómo la locura puede contagiarse, traspasarse de un personaje a otro y con ella una gama de percepciones alteradas. Como resultado la solidez corpórea del mundo exterior se licua, lo sólido se vuelve líquido para los protagonistas. El relato trata a su vez del par razón/emoción, del que tenemos referentes en Unamuno, Platón y Antonio Damasio en El error de Descartes.

El tercer ejemplo, La playa y el otro ${ }^{13}$, también publicado en A los fantasmas se les mata publicando juega con el concepto del cuerpo como el primer otro de Ortega, pensamiento de corte platónico. ¿Pero es realmente el otro? En este relato, las referencias filosóficas son manifiestas. El narrador y los personajes hablan de filosofía abiertamente, de Platón, de El Parménides, de Ortega y Gasset. Trata de cómo la playa es la mostración pública del desnudo colectivo del otro que es el cuerpo, y de la relación de cada uno con su otro y con el de los demás. Se ambienta en la playa y en un bar donde, en madrugadas de bohemia, los clientes asiduos desnudan sus cuerpos y se fotografían por las calles o en la playa de noche, para posteriormente exhibir dichas fotografías en el bar, dándose la coincidencia de que puedes tomar una copa y el señor acodado junto a ti es el mismo que posa desnudo en la serie de fotografías que se proyectan en un monitor tras la barra. La proximidad del bar con la playa,

11 PÉREZ CASTAÑEDA, SANDRA (2012). La ciudad que rompe sueños. Alhulia. Granada.

12 PÉREZ CASTAÑEDA, SANDRA (2013). La burla. A los fantasmas se les mata publicando. Alhulia. Granada.

13 PÉREZ CASTAÑEDA, SANDRA (2013) La playa. A los fantasmas se les mata publicando. Alhulia. Granada. 
le hace heredero del relajo con el otro que es el cuerpo que se respira en el entorno playero. En el relato se abordan aspectos filosóficos relativos al cuerpo. El cuerpo como cárcel o el alma como cárcel del cuerpo. El dualismo cartesiano, la reunificación de Scheler. La dimensión material del hombre, la más puramente sensible. Su satanización. El gusto. Las modas. El bien y el mal. La desnudez y el encubrimiento del cuerpo en el invierno. La moral que rodea lo corpóreo. Lo escatológico. La reconquista de la geneología.

En narración y fuera de ella, nos manejamos con el cuerpo tanto en la consciencia de su presencia como en la inconsciencia de la misma. Para pasar de un estadio a otro debemos hacer uso de la atención y la intención. Modos de la fenomenología de Husserl. Así que para patentizar el cuerpo, que siempre está, que no se esconde de nosotros, tenemos que volvernos hacia él. Nietzsche dice: «El cuerpo soy yo». Wittgestein en Sobre la certeza discurriendo en la diferencia entre saber y certeza dice que la constancia del cuerpo no es discursiva ${ }^{14}$. «No sé cómo se ha de utilizar: «Tengo un cuerpo» ${ }^{15}$ ». ««Sé que tengo un pie

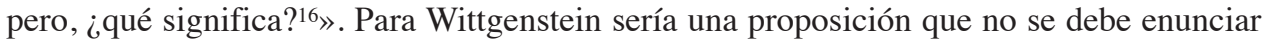
pero que se hace con fines mostrativos. «Si sabes que aquí hay una mano te concederemos todo lo demás» ${ }^{17}$ enunciado de inicio de Sobre la certeza. No podemos dudar de que tenemos cuerpo y no necesitamos saber de materia para saber de nuestra corporeidad, ya que el cuerpo es el no discurso. El cuerpo sería una certeza animal ${ }^{18}$, como un tipo de seguridad que no tiene y no le cabe justificación, que no posee razones. La certeza animal es aquella sobre la que nuestra vida tiene sentido y donde no entra el escepticismo. Referirnos al cuerpo es un enunciado hecho, sin duda legítima para Wittgenstein, sin embargo, requerimos de un retorcimiento para patentizar nuestro cuerpo y el cuerpo de los personajes.

Seamos o no conscientes del cuerpo este forma parte de nuestra identidad. Paul Ricoeur desarrolla en Tiempo y narración el concepto de identidad narrativa. Dice Ricoeur que preguntarse quién es alguien exige narrar sus obras. Narrar da permanencia y se pierde el fenomenismo de la diversidad de estados. La trama narrativa hace del sujeto un ipse, un sí mismo, que unifica la heterogeneidad, los cambios y la diversidad episódica ${ }^{19}$. Trasladado al tema que nos ocupa, podemos afirmar que el cuerpo es un ipse, que persiste al cambiar, y, en su ipseidad incluye cambio, mutabilidad y cohesión ${ }^{20}$. La narración asienta un cuerpo y una identidad a través de su transcurso.

En Tiempo y narración las soluciones a la problemática de las aporías del tiempo pasan por la vía de la narración. Ricoeur asegura que lo fecundo de lo poético obedece a que los objetivos, métodos y rigor difieren de la filosofía, gozando por ello la ficción de una libertad de configuración privilegiada para dar cuenta de lo humano. A la filosofía se le

14 WITTGENSTEIN, LUDWING. (1998). Sobre la certeza. Gedisa. Barcelona.

15 WITTGENSTEIN, LUDWING. (1998). Sobre la certeza. Gedisa. Barcelona, p. 34 [258].

16 WITTGENSTEIN, LUDWING. (1998). Sobre la certeza. Gedisa. Barcelona, p. 49 [379].

17 WITTGENSTEIN, LUDWING. (1998). Sobre la certeza. Gedisa. Barcelona, p. 26 [1].

18 WITTGENSTEIN, LUDWING. (1998). Sobre la certeza. Gedisa. Barcelona, p. 47 [359] «Pero ello significa que quiero considerarlo como algo que yace más allá de lo justificado, y de lo injustificado; como, por decirlo de algún modo, algo animal».

19 RICOEUR, PAUL (1996) Tiempo y narración III. El tiempo narrado. Siglo veintiuno. Madrid, p. 630.

20 RICOEUR, PAUL (1996) Tiempo y narración III. El tiempo narrado. Siglo veintiuno. Madrid, p. 998. 
exige que aspire a verdad, a la literatura que convenza con verosimilitud. Aristóteles prima lo verosímil o lo necesario a cualquier otro factor en la trama ${ }^{21}$.

Para Ricoeur la ontología heideggeriana es clave para la comprensión de la existencia. Comenzábamos formalizando la cercanía entre Heidegger y el objeto que nos ocupa al afirmar que todo personaje narrativo es un Dasein arrojado al mundo, asumiendo la terminología de El ser y el tiempo ${ }^{22}$. El ser-ah $\imath^{23}$ es «la relación del ser con su ser ${ }^{24} \mathrm{y}$, en virtud de su esencia, existe como arrojado y en decadencia; conceptos que podemos aplicar al cuerpo. El mundo al que ha sido arrojado es parte integrante del ser, «un momento constitutivo del ser-ahí» ${ }^{25}$. Del mismo modo, los personajes existen en un mundo que les constituye y que, además, ha sido creado para ellos. Cabría objetar esta conexión entre Heidegger y la narración y poner en entredicho la existencia de un personaje, lo que implicaría un proyecto de clarificación del concepto existencia. No es el objetivo de esta investigación especular si los personajes son reales o simulados, o si nosotros somos o no ficciones, o si el mundo es realidad o representación. Imitar de forma activa es el carácter genérico que da Aristóteles a la poética, representación de la acción ${ }^{26}$. Existencia, para Heidegger, significa poder-ser ${ }^{27}$. La existencia del personaje deja de ser cuestionable si atendemos a que consigue replegarse en el mundo del lector a través de un juego de interpretación identificativa que pone en duda si tienen o no ontología y si el carácter óntico de un personaje sea únicamente el negro tintado sobre el papel blanco de un libro o los sonidos articulados de un relato oral. Cabría entonces objetar que un personaje podría tener realización existencial pero no existenciaria, analizada, la cual distingue al Dasein del resto de entes ${ }^{28}$. En narración el análisis existencial se da, que quede patentizado o aparezca en el subtexto es cuestión de estilo. Podría entenderse que ese carácter existenciario es simulado, que ser con su ser del personaje-Dasein está mediado por el autor ${ }^{29}$. En mi opinión, la creación en general y en particular la que nos ocupa, la narrativa, tiene tal carga ontológica que es equiparable al delante-de-sí del ser-ahí. ¿No es esta posición acaso la que adopta el autor frente al folio en blanco al componer un mundo? Si la tarea heideggeriana es liberar al ser del olvido y el disimulo, propósito de $E l$

21 RICOEUR, PAUL (1987)Tiempo y narración I. Configuración del tiempo en el relato histórico. Cristiandad Madrid, p. 95.

22 HEIDEGGER, MARTIN (1989) El ser y el tiempo. Trad. José Gaos. FCE. Madrid.

23 Marcamos en cursiva los existenciarios heideggerianos, estructuras para el análisis existenciario.

24 HEIDEGGER, MARTIN (1989) El ser y el tiempo. Trad. José Gaos. FCE. Madrid, p. [12] (27).

25 HEIDEGGER, MARTIN (1989) El ser y el tiempo. Trad. José Gaos. FCE. Madrid, p. [52] (73).

26 Ricoeur tiene muy en cuenta la mímesis en Tiempo y narración ya que se basa en la Poética de Aristóteles. Define Ricoeur mímesis a partir de Aristóteles como imitación o representación de la acción, proceso activo de imitar o representar. RICOEUR, PAUL (1987)Tiempo y narración I. Configuración del tiempo en el relato histórico. Cristiandad Madrid, p. 86.

27 «Existencia significa poder-ser, y así, también poder-ser auténtico». HEIDEGGER, MARTIN (1989) El ser y el tiempo. Trad. José Gaos. FCE. Madrid, p. [233].

28 Ricoeur distingue existencial de existenciario, afirmando que existencial es una elección concreta de una manera de estar-en-el-mundo, mientras que existenciario es el análisis de las estructuras que distinguen al serahi de los otros entes. RICOEUR, PAUL (1996) Tiempo y narración III. El tiempo narrado. Siglo veintiuno. Madrid, p. 725.

29 Traemos a colación la recreación de esta disyuntiva que consigue Unamuno al hacer que su personaje le visita para preguntarle si es una creación y exigir a su creador que no le mate, como muchos de nosotros apelamos al nuestro en nuestras dificultades mundanas. UNAMUNO, MIGUEL (1982) Niebla. Ed. M.J.Valdés. Cátedra. Madrid. 
ser y el tiempo, bien podemos servirnos de él para liberar al cuerpo de su ocultación en el texto a través de la intencionalidad. La ontología heideggeriana no es posible más que como fenomenología ${ }^{30}$. En un relato atendemos a la exhibición del ser en un mundo en un tiempo. Tiene carácter ontológico.

El existenciario heideggeriano más fecundo para destapar al cuerpo en la narración es el Cuidado, que se vincula al proyecto primordial de la comprensión del ser. Conforma la mundaneidad del ser-en-el-mundo y fija las cosas utilizables por el ser-ahí. En narrativa el fenoménico es la existencia del personaje y su mundo. El Cuidado es para Heidegger la estructura totalizadora de la existencia ya que saca al ser-ahí sale de la pasividad original de ser-arrojado-al-mundo y lo orienta hacia el proyecto primario de posibilización, el poder-ser-hacer-posible que posibilita la experiencia humana. Los personajes son también, básicamente, posibilidades de ser y de acción. La primera implicación del Cuidado es serdelante-de-sí por el que el ser-ahí tiende a venir hacia sí mismo según sus posibilidades más propias y se encara como totalidad hacia su futuro. Sin el Cuidado, las posibilidades del ser se quedan en suspenso, se aplazan ${ }^{31}$. Cuando Heidegger habla del olvido del ser, se refiere al olvido de su finitud y del sentido originario del Cuidado. El Delante-de-sí conlleva una confrontación con el cuerpo. Su rescate del olvido. Es el retorcimiento para dar cuenta de su presencia y necesidad. Aunque en Heidegger la muerte es fundamentalmente la de uno mismo, también contempla la de otros, «los acabados y aún presentes», cuya muerte es resolución anticipatoria de la nuestra. Apelar a la muerte de los otros es, en el plano de la historicidad, apelar a la nuestra.

Heidegger considera el presente la categoría menos apta para el análisis originario y la fenomenología directa la menos auténtica ${ }^{32}$. En su lugar, toma de partida para su fenomenología hermenéutica el futuro. Conceptúa los tiempos como éxtasis, los renombra y les confiere dinamismo, aspecto verbal y adverbial. El ad-venir, el haber-sido y el presentar. De modo horizontal, el éxtasis del futuro es el fuera-de-sí, condición primaria de ser-arrojadoal-mundo. El éxtasis del presente, el presentar. Y el éxtasis del pasado, en el haber-sido ${ }^{33}$. En paralelo, discurren en vertical la temporalidad del tiempo mortal, la historicidad del tiempo histórico ontológico y la intratemporalidad del tiempo cósmico. Todos constituyen al Dasein.

$\mathrm{Al}$ igual que en el análisis existenciario, en narración el presente si no es el tiempo menos apto, es poco frecuente. También muy pocas se orientan al futuro. La mayoría discurren en pasado, aunque funcione como un presente en progresión, se apunta al futuro, al éxtasis del futuro, ya que el devenir supone una incógnita. La resolución se va anticipando en la trama pero se desconoce, salvo excepciones. En Crónica de una muerte anunciada (1981) Gabriel García Márquez arranca afirmando la muerte del protagonista. En Heidegger, el futuro implica al pasado y se aplaza el presente. El por-venir reclama al haber-sido. Estas pautas se dan en narrativa necesariamente. Son requisitos de la coherencia y la verosimilitud. El futuro del pasado está en cualquier despliegue de tiempo narrativo ${ }^{34}$. La narración, como el tiempo heideggeriano, posee ese carácter de éxtasis, de un fuera-de-sí constituyente que

30 HEIDEGGER, MARTIN (1989) El ser y el tiempo. Trad. José Gaos. FCE. Madrid, p. [35] (53).

31 HEIDEGGER, MARTIN (1989) El ser y el tiempo. Trad. José Gaos. FCE. Madrid, p. [35] (53).

32 RICOEUR, PAUL (1996)Tiempo y narración III. El tiempo narrado. Siglo veintiuno. Madrid, p. 724

33 RICOEUR, PAUL (1996)Tiempo y narración III. El tiempo narrado. Siglo veintiuno. Madrid, p. 751.

34 RICOEUR, PAUL (1996)Tiempo y narración III. El tiempo narrado. Siglo veintiuno. Madrid, p. 722. 
conforma una exhibición, un exteriorizar, una derrelicción. Es un salir para volver al objeto, como la fenomenología de Husserl, como el círculo en torno al ser-ahí que dibuja la ontología hermenéutica; mímesis configurativa que regresa en refiguración.

El primer olvido del ser-ahí es su condición de arrojado; el aturdimiento consecuente procura una existencia inauténtica, no originaria. Como el personaje que se olvida de su condición ontológica de creación de ficción, excepto casos contados como el protagonista de Niebla (1914). En narración, por la propia esencia del narrar, por ser imitación, los personajes están arrojados a ser un fuera-de-sí. El conflicto de la trama les saca de un estado pasivo y los lleva a acción, sin elección alguna y sabiéndose mortal. El que no, paga con la muerte, como en la vida. Sin embargo, en la existencia del ser-ahí no hay garantía existenciaria $a$ fortiori. En términos generales, el relato representa a un ser-ahí en existencia auténtica en busca de lo originario. Es intención, imitación activa. Sin embargo, el Dasein en su olvido del ser reniega de su inherente constitución. Por el olvido del ser, el ser-ahí termina siendo un otro que no el arrojado, otro que no el ser-para-la-muerte. Paradójico que la imitación cumpla existencia auténtica y lo que imita, la propia existencia, no. En narrativa, el fuerade-sí constituye su legitimidad necesariamente. La totalidad del ser-ahí es morir. «Finar, en el sentido de morir, constituye la totalidad del ser-ahí» [240]. La prueba máxima del ser-untodo auténtico del ser-ahí, cuyo límite es ser-para-la-muerte, nuestra finitud. En narrativa la muerte del personaje, su acabamiento corpóreo.

Podemos encontrar conexiones útiles entre Heidegger y Aristóteles. Para el primero es fundamental lo posible y para el segundo la posibilización. Existencia para Heidegger significa poder-ser y en Aristóteles la trama da respuesta a lo posible hasta hacerlo efectivo. «No es tarea del poeta decir lo que ya se ha sucedido, sino aquello que podría suceder, esto es, lo posible según la probabilidad o la necesidad» ${ }^{35}$. Poética comienza diciendo Aristóteles que todos los géneros poéticos son potencia. Dynamis que en su teoría se opone al acto, enérgeia. P63 [10] ${ }^{36}$. En Heidegger, lo posible del ad-venir tiene su raíz en las posibilidades del haber-sido y del presentar. El ser-ahí se transmite de sí mismo, según posibilidades heredadas y elegidas. Emparentado al «uno después del otro» de la trama aristotélica. En Heidegger hay equilibrio entre lo que todavía puede ser y lo que «ya (...) no» ${ }^{37}$. Ese equilibrio que para Aristóteles garantiza la verosimilitud de la trama. Otras similitud entre ambos autores radica en la totalidad existencial del ser-integral y el ser-un-todo, y la concepción aristotélica de trama como un todo, - lo que tiene principio, medio y fin, siendo «medio» el cambio, la temporalidad, la discordancia-. Este todo aristotélico puede ligarse a la historicidad del ser-ahí entendida por Heidegger como el alargamiento de un «entre-dos», el entre-nacer-y-morir ${ }^{38}$. El «entre-dos» es, por tanto, existencia, pero también narración. Aristóteles exige a la trama plenitud, totalidad, extensión apropiada, conexión interna y coherencia ${ }^{39}$. El «entre-dos» heideggeriano es cohesión y desarrollo, permanencia y cambio. Ricoeur observa similitudes con Dilthey en la idea de cohesión de vida. Decía Dilthey que

35 ARISTÓTELES (2004) Poética. Trad y Ed. Salvador Mas. Biblioteca nueva. Madrid, p. 85 [1451b].

36 ARISTÓTELES (2004) Poética. Trad y Ed. Salvador Mas. Biblioteca nueva. Madrid, p. 63 [10].

37 ARISTÓTELES (2004) Poética. Trad y Ed. Salvador Mas. Biblioteca nueva. Madrid, p. 742.

38 RICOEUR, PAUL (1996) Tiempo y narración III. El tiempo narrado. Siglo veintiuno. Madrid, p. 736.

39 RICOEUR, PAUL (1987) Tiempo y narración I. Configuración del tiempo en el relato histórico. Cristiandad Madrid, pp. 94-106. 
una vida ha de contarse justo antes de morir; Heidegger, que hay que vivir atendiendo a que morirás. Para Heidegger la cuestión de la cohesión del ser-ahí es problema ontológico y no de las ciencias humanas, Geisteswissenschaften ${ }^{40}$. El «entre-dos» también se vincula con la identidad narrativa de Ricoeur, ya que dispone una identidad ontológica derivada del estiramiento, la mutabilidad y la estabilidad del sí mismo, el quién del ser-ahí, del ipse. El idem, la identidad sustancial, es innatural ${ }^{41}$. El ser-ahí se presenta estable en su ipseidad.

Como conclusión a esta aproximación al asunto del cuerpo en las narraciones, me gustaría rescatar la importancia del mito en filosofía. Ambos comparten simiente, el logos. Ricoeur admite que la narración ofrece respuestas productivas a asuntos filosóficos y sugiere que la filosofía abandonó al mito demasiado pronto sin merecerlo ${ }^{42}$ y propone el lirismo del pensamiento meditador como posibilidad de acercamiento a cuestiones aporéticas. Yo apoyo esta tesis. La filosofía puede nutrirse de la libertad narrativa y no renunciar al mito cuando es un recurso a añadir en lugar de a desquitar.

\section{Bibliografía}

Aristóteles. Poética. Ed. y Trad. Salvador Mas. Ed. Biblioteca Nueva. Madrid, 2004.

Heidegger, M. El ser y el tiempo. Trad. cast. de José Gaos. FCE, 1989. 1ª Ed. Sein und Zeit 1927 Ed. Tubinga.

Ricoeur, P. Tiempo y Narración I. Configuración del tiempo en el relato histórico. Madrid. Ed. Cristiandad, 1987.

Ricoeur, P. Tiempo y Narración II. Configuración del tiempo en el relato de ficción. Madrid. Ed. Cristiandad, 1987.

Ricoeur, P. Tiempo y Narración III. El tiempo narrado. Madrid. Ed. Siglo veintiuno, 1996. Traducción Agustín Neira.

Unamuno, M. Niebla. Edición de M.J. Valdés, Madrid, Cátedra, 1892.

Wittgenstein, L. Sobre la certeza. Ed. Gedisa. Barcelona, 1998.

40 RICOEUR, PAUL (1996) Tiempo y narración III. El tiempo narrado. Siglo veintiuno. Madrid, p. 746.

41 RICOEUR, PAUL (1996) Tiempo y narración III. El tiempo narrado. Siglo veintiuno. Madrid, p. 998.

42 Mythos es la disposición de hechos en un sistema. Es un proceso de síntesis. Ricoeur traduce el mythos aristotélico como trama para evitar la confusión con el mito clásico. Tampoco utiliza el término historia que puede entenderse como narración basada en hechos sucedidos en el pasado, ya que en francés no existe la diferencia del inglés entre story y history. 
